\title{
LAYOUT NO EDITORIAL DIGITAL: uma releitura de conceitos clássicos de tipografia e grid para um projeto digital
}

\author{
Genilda Oliveira de Araujo \\ Universidade do Estado de Santa Catarina - UDESC \\ genilda@gmail.com \\ Gabriela Botelho Mager \\ Universidade do Estado de Santa Catarina - UDESC \\ gabriela.mager@udesc.br
}

\begin{abstract}
Resumo: A evolução da qualidade das telas digitais, o aumento da velocidade da web e o surgimento de inúmeros modelos de computadores e dispositivos móveis proporcionaram ao mercado editorial novas possibilidades para oferecer conteúdo aos leitores. O artigo compara o desenvolvimento da composição gráfica do meio impresso com o digital a partir do formato de página, a área de texto, grid e tipografia. Conclui-se que o trabalho do designer nos projetos editoriais para meio digital mantém os fundamentos da composição tipográfica para meio impresso, mas busca estruturar layouts mais dinâmicos e flexíveis, garantindo adaptação à variedade de formatos de telas e equipamentos.
\end{abstract}

Palavras-chave: design, editorial digital, tipografia.

\begin{abstract}
The evolution of quality of digital screens, the increasing web speed and the emergence of several models of computers and mobile devices provided new possibilities for publishing to deliver content to readers. The article compares the design of graphical composition in the printed media with its digital version, discussing the page format, the text area, grid and typography. We conclude that the designer's work in digital projects can be based on the same fundamentals of typesetting for the print medium, but seeks to structure layouts in a more dynamic and flexible way, handling a variety of digital screens formats and equipment.
\end{abstract}

Keywords: design, digital editorial, typography.

\section{INTRODUÇÃO}

A partir dos anos 80, quando começaram a se desenvolver os principais estudos e guias referentes a usabilidade do meio digital, sempre se tratou o computador como uma mídia diferente do impresso por ser um ambiente parco à leitura. Problemas 
relacionados a radiação de luz e a atualização da imagem na tela, cuja oscilação na frequência pode causar o efeito "flicker", cansavam rapidamente a visão ${ }^{1}$. Além disso, a baixa densidade das telas, restritas a apresentar apenas 72 pixels por polegada (PPI), deixava qualquer imagem e, especialmente, o texto, com um aspecto visual inferior ao das impressões de livros e de revistas, feitas geralmente com 300 pontos por polegada (DPI). Este fato fazia com que não apenas as delicadas serifas de uma fonte como a Garamond não pudessem ser visualizadas com clareza, mas também, segundo Nielsen ${ }^{2}$, reduzia em $25 \%$ a nossa velocidade de leitura, ocasionando a sensação de que ler no computador era mais cansativo e desagradável do que ler um impresso. 0 próprio Nielsen propunha que se usasse uma linguagem sucinta na web escrevendo $50 \%$ menos texto do que para um material impresso, mostrando que, pelo menos naquele momento, a mídia digital não era o espaço adequado para a publicação de livros e revistas amplamente ricos em conteúdo.

Projeções feitas na década de 90 indicavam que o surgimento de telas de alta qualidade mudaria essa relação do leitor com a mídia digital e que poderiam resultar, junto com o aumento da velocidade na web, no fim dos jornais, revistas, livros e dos canais de televisão, sendo substituídos por uma única mídia integrada ${ }^{3}$. Deixando a parte estas previsões dramáticas a respeito da morte do impresso, é inegável que os últimos eventos no campo da tecnologia colocaram em curso uma mudança no segmento editorial, oferecendo ao leitor uma nova escolha: a plataforma onde prefere consumir a sua publicação favorita.

Atualmente, as telas de LCD substituíram as de CRT, adotando uma frequência de atualização de imagem em torno de $200 \mathrm{~Hz}$, o que torna quase imperceptível a oscilação aos olhos, oferendo mais conforto para a leitura. Além disso, a disseminação de telas com alta densidade de pixels está em curso. O primeiro computador voltado para um grande público com esta característica foi lançado em 2012 pela Apple: um notebook com 220PPI. Este patamar de densidade também já era encontrado no IPhone, como 326 PPI a partir de 2010. No entanto, estas transformações tecnológicas começaram a afetar o segmento editorial a partir do lançamento do iPad em 2010, que criou um mercado para dispositivos tão leves e portáveis quanto um livro ou uma revista, tendo se equiparado a estes em termos de leiturabilidade em 2012 ao adotar uma densidade de tela de 264PPI. A partir daí, o que se viu foi o lançamento de uma infinidade de desktops, notebooks, tablets e smartphones com telas de alta qualidade, produzidos pelos mais variados fabricantes.

A popularização destes gadgets já se revela em números no mercado editorial. Segundo dados da Alliance Audited Media $^{4}$, órgão que verifica e audita a circulação da mídia nos Estados Unidos, na primeira metade de 2013 o número de revistas adquiridas caiu em $1 \%$, somando as versões impressa e digital. Dentro deste montante, as assinaturas impressas caíram $0.1 \%$, a venda avulsa nas bancas caiu em $10 \%$ e 0 número de assinaturas de edições digitais dobrou, passando de $1.7 \%$ da circulação total para 3.3\%. No Reino Unido, dados do Audit Bureau of Circulations ${ }^{5}$ referentes ao primeiro semestre de 2013, mostram uma tendência similar de declínio na circulação, somando as edições impressa e digital. No entanto, uma análise da composição deste

\footnotetext{
${ }^{1}$ DIECKMANN, 2014

${ }^{2}$ NIELSENa, 1997

${ }^{3}$ NIELSENb, 1998

${ }^{4}$ ALLIANCE FOR AUDITED MEDIA, 2013

${ }^{5}$ THE GUARDIAN, 2013
} 
total, revela que diversas publicações já contam um percentual expressivo de sua circulação em meio digital, como: "How it Works" (21\%), "Total Film" (16.8\%), "Wired" (14.1\%), "BBC History Magazine" (10.4\%), "GQ" (9.4\%) e "Vanity Fair" (8.6\%).

Neste contexto, é mais do que natural focar a atenção para as novas necessidades de um projeto editorial, uma vez que o próprio público já está incorporando o hábito da leitura digital. O cenário é de transição. Se por um lado, os guidelines de usabilidade para a tipografia on-line precisam ser revistos e atualizados ${ }^{6}$, por outro, temos uma enorme bagagem tipográfica que agora pode ser aplicada. As técnicas de layout para o digital também evoluíram e já se tem liberdade para moldar o espaço da tela conforme um conceito, convertido na estrutura de um grid. Juntandose a isso, surgem as peculiaridades da própria mídia. Além da interatividade, da hipertextualidade e da confluência com material multimídia e com as mídias sociais, tem-se uma multiplicidade de dispositivos tecnológicos que o público espera fazer uso para a visualização dos mais diversos tipos de publicação.

Diante da nova realidade dos projetos editoriais, este artigo busca contribuir para a discussão do design editorial revisando os principais aspectos de um projeto impresso e reapresentando-os sob a ótica digital, resgatando elementos aplicáveis da herança tipográfica, além de comentar diferenças práticas, sintáticas e semânticas entre projetos elaborados para as duas mídias.

\section{PRINCÍPIOS DE COMPOSIÇÃO DO DESIGN EDITORIAL}

Até bem pouco tempo, editorial era basicamente concebido como sinônimo de material impresso. Era o segmento do design amplamente reconhecido pelo projeto de livros, revistas e jornais, tendo sempre se caracterizado por ser um tipo de projeto que trata de conferir forma visual aos produtos de informação. Neste sentido, não há mudança com a adoção da plataforma digital. Continuará tratando da questão do suporte à leitura do conteúdo, da tessitura da página. Continuará lidando com o problema de compor o conteúdo no espaço, independente de ser uma página de papel ou a tela de um dispositivo digital.

Posto isso, a comparação entre o impresso e o digital será feita nos principais elementos modelados ao se elaborar um projeto editorial e que, segundo Haslam ${ }^{7}$, compõem a paleta do designer: o formato; a definição da área de texto e a construção da grade; o arranjo tipográfico; o tamanho do caractere tipográfico e o tipo de letra.

\subsection{Formato de página}

O formato estabelece a relação entre altura e largura da página ${ }^{8}$ e é uma das primeiras questões pensadas durante um projeto editorial impresso, sendo, no âmbito digital, um elemento amplamente afetado pela tecnologia.

Um dos primeiros aspectos que o meio digital modifica é a forma de interação e percepção do conteúdo. Fazendo uma analogia histórica, na antiguidade, textos e documentos eram escritos e armazenados no formato de rolos. Foi a partir do século IV d.C. que surgiu o formato de livro conhecido hoje, chamado de codex, que nada mais é do que um conjunto de folhas individuais, unidas e protegidas por uma capa

\footnotetext{
${ }^{6}$ NIELSENc, 2012

${ }^{7}$ HASLAM, 2007, p.31

${ }^{8}$ HASLAM, 2007, p.31
} 
protetora $^{9}$. Esta mudança de formato, embora aparentemente simples, significou a divisão do conteúdo escrito em unidades padronizadas de transmissão. Ou seja, no momento em que o rolo foi dividido, rompeu-se a fluidez do discurso e se criaram elementos individualizados que são agrupados para formar o livro: as páginas. Para sua concatenação, que representa a remontagem e reordenação do discurso, surgiram vários elementos como números de páginas, cabeçalhos e índices ${ }^{10}$. Com a adoção do digital, em certa medida, pode-se voltar a tratar a informação da mesma forma que na antiguidade: como um discurso contínuo, rolado ao se manipular o mouse ou por gestos em telas touch, sendo este o padrão para a apresentação de conteúdo na web.

Outro aspecto que diferencia o editorial impresso do digital é o controle sobre a escolha do formato da publicação. Em um projeto impresso, diversos fatores podem influenciar nesta decisão. O primeiro deles é o aproveitamento de papel, que leva a proposição de dimensões economicamente viáveis de acordo com os tamanhos de fábrica disponíveis no mercado, tais como o AA $(76 \times 112 \mathrm{~cm})$ e o BB $(66 \times 96 \mathrm{~cm})^{11}$. Há questões práticas, ligadas às necessidades de manuseio do produto, como portabilidade, ou à natureza do conteúdo, que pode ser composto por mapas ou imagens que requeiram páginas amplas para uma visualização adequada. Há fatores de ordem semântica e conceitual. Por fim, tem-se ainda a possibilidade da adoção de proporções harmônicas derivadas da seção áurea; de formas geométricas como quadrado, pentágono, hexágono e octógono; ou de intervalos musicais de quarta, quinta, sexta e sétima ${ }^{12}$. Em resumo, o designer tem muito a considerar. No entanto, após a escolha ser feita, o projeto gráfico é desenvolvido com base no formato definido, que será exatamente o que chegará às mãos do leitor do editorial.

Comparativamente, em um projeto digital, o designer não arbitra sobre o formato, pois o mesmo é dado pelo dispositivo usado pelo leitor para visualizar o conteúdo. A título de exemplificação das principais variações encontradas no mercado, serão considerados quatro tipos de dispositivos: desktops, notebooks, tablets e smartphones. No caso de desktops, as telas geralmente variam entre 15 e 27 polegadas. Para notebooks, se for incluído o grupo dos netbooks, comumente se encontra telas entre 11 e 17 polegadas. No caso de tablets, existem modelos de 7 a 12 polegadas. No caso de smartphones, de 3 a 6 polegadas.

Neste cenário, com variações de tela entre 3 e 27 polegadas, ficam evidentes algumas questões. A primeira é que não é possível utilizar o mesmo layout para esta gama de dispositivos. Telas grandes, assim como grandes formatos impressos, requerem maior volume de informação do que telas pequenas ou edições de bolso. Por outro lado, esta mesma variação impõe outro problema: pode ser inviável construir layouts específicos para todos os tamanhos disponíveis. Assim, a nova situação requer uma abordagem diferente, baseada em layouts mais dinâmicos que se adaptem às telas onde o editorial está sendo visualizado.

\subsection{Margens e Mancha Gráfica}

Após a seleção do formato do impresso, que fixa as dimensões externas da página, trabalha-se na grade ou grid, determinando suas divisões internas ${ }^{13}$. Um dos

\footnotetext{
${ }^{9}$ WOOD, 2007

${ }^{10}$ CHAPPELL, 1999, p. 39

${ }^{11}$ OLIVEIRA, 2002, p.85.

${ }^{12}$ BRINGHURST, 2005, p.169.

${ }^{13}$ HASLAM, 2007, p. 42.
} 
aspectos desta organização interna é a delimitação das proporções da mancha gráfica, que corresponde à área de ocupação básica da página, desconsiderando-se elementos complementares como numeração e títulos correntes ${ }^{14}$. São as margens que fazem esta delimitação, tendo por função: "amarrar o bloco de texto à página e amarrar as páginas opostas uma à outra com a força de suas proporções" e "proteger o bloco de texto facilitando a visualização do leitor e tornando o manuseio conveniente" ${ }^{\prime 15}$.

No contexto digital, o uso do espaço em branco das margens para proteção e direcionamento do olhar para a mancha gráfica funciona tal como no impresso, pois, em ambos os casos, é válida a Lei da Segregação da Gestalt, baseada na capacidade perceptiva de separar, identificar e evidenciar unidades formais de um todo compositivo $^{16}$. O espaço em branco acrescenta uma aura de valor quando utilizado generosamente. "Usado estrategicamente, catapulta as ideias da página para a mente do leitor, porque as esclarece e aumenta seu impacto" ${ }^{17}$.

A questão do manuseio e do espaço para a pega é difícil de ser abordada no digital, pois depende de características físicas do dispositivo a ser usado para a visualização, o que não pode ser previsto no momento do projeto. Por fim, a necessidade da amarração de páginas opostas, contribuindo para a construção da página dupla como unidade visual, deixa de fazer sentido. Na prática, o que se tem nos dispositivos digitais é uma tela que analogamente corresponde a uma única folha de papel, a um espaço contínuo para dispor o conteúdo da publicação, e não duas páginas espelhadas presas por uma lombada. Por mais que se possa usar a metáfora do impresso e dividir este espaço em dois, o que se terá é um simulacro de página dupla e não um real eixo central a partir do qual se pode trabalhar simetria ou assimetria.

\subsection{Construindo o grid impresso}

Além das proporções da mancha gráfica, os sistemas básicos de grid determinam o número de colunas na qual se dividirá o espaço; o comprimento ou a largura das colunas; sua profundidade ou altura; bem como a espessura do intervalo entre elas ${ }^{18}$. Focando na leiturabilidade do conteúdo, estas questões não são decididas aleatoriamente, mas conjuntamente tratadas, considerando sua forte dependência em relação a tipografia escolhida, seu corpo e sua entrelinha.

Para Muller-Brockmann ${ }^{19}$, um dos maiores teóricos na área de sistemas de grid, encontrar o comprimento correto de linha e, consequentemente da coluna, é um dos mais importantes problemas tipográficos. Tanto linhas de texto muito curtas quanto muito largas causam esforço ao leitor, que se cansa com mais rapidez, provocando perda na qualidade da comunicação e memorização. No caso das linhas longas, o olho acha a leitura cansativa porque emprega muita energia para manter a linha em vista por uma longa distância. Em linhas muito curtas, o fluxo de leitura é interrompido ao se ter que trocar de linha muito rapidamente.

As métricas para definição do comprimento ideal são dadas em termos de números de caracteres por linha. Quando se trata de uma página com uma única coluna de texto, comumente presente em livros de romance, o intervalo de 45 a 75

\footnotetext{
${ }^{14}$ ADG, p. 71.

${ }^{15}$ BRINGHURST, 2005, p.181

${ }^{16}$ GOMES FILHO, Gestalt do Objeto, p.30.

${ }^{17}$ WHITE, 2005, p. 24.

${ }^{18}$ HASLAM, 2007, p. 42.

${ }_{19}$ MULLER-BROCKMANN, 2007, p. 30
} 
caracteres por linha, contando letras e espaços, é reconhecido como satisfatório e recomendado. A medida ideal é a linha de 66 caracteres. Em casos de páginas com múltiplas colunas, como as frequentemente encontradas em revistas e jornais, a faixa recomendada varia de 40 a 50 caracteres por linha ${ }^{20}$.

Assim, conforme esquematizado nas figuras $1 \mathrm{a}$ e1b, o mesmo formato pode ser dividido em diferentes números de colunas. A divisão em duas colunas, quando comparada com uma coluna, provavelmente irá requerer uma redução no corpo da letra, nas margens ou em ambos para que a métrica do número de caracteres por linha seja respeitada. Por sua vez, se o mesmo formato for dividido em três colunas, o corpo necessário para manter a métrica pode se revelar pequeno demais para garantir boa leiturabilidade. Assim, um ajuste no próprio formato, como ilustrado na figura 1c, pode ser necessário caso se queira trabalhar com três colunas. Por outro lado, neste formato maior, uma diagramação em uma única coluna, iria requerer um corpo maior do que o usado na figura 1 .
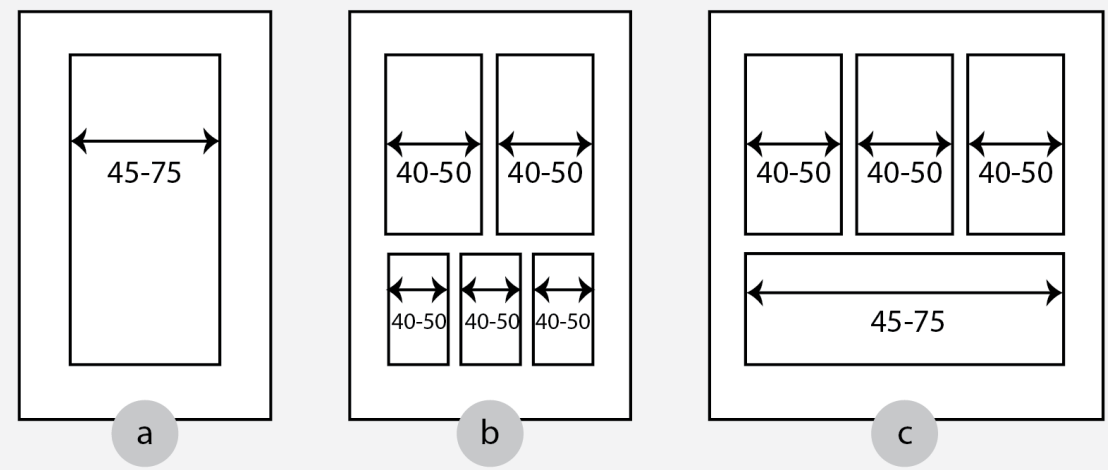

Figura 1 - Largura das colunas em números de caracteres.

Fonte: Elaborado pelo autor, com base na pesquisa realizada.

O ajuste vertical do grid, que define a profundidade ou altura das colunas, é influenciado por outra medida tipográfica: a entrelinha. Ela é a unidade rítmica básica da página, definindo a distância entre uma linha de base a outra no texto ${ }^{21}$. Uma entrelinha muito pequena reduz a leiturabilidade porque mantém simultaneamente no campo de visão de precisão (foco) mais do que uma linha de texto. Quando as linhas estão exageradamente espaçadas, o leitor tem dificuldade de fazer a ligação com a próxima linha. Assim, uma entrelinha adequada ajuda a manter a concentração naquilo que está sendo lido e leva suavemente o olhar de uma linha a outra ${ }^{22}$.

É importante ponderar a entrelinha observando os diversos fatores que influenciam a percepção visual do texto: colunas mais largas requerem mais entrelinha do que colunas mais estreitas; tipos mais pesados precisam de mais entrelinha do que tipos mais leves; tipos de corpo grande pedem uma entrelinha maior do que tipos de corpo pequeno e fontes sem serifa pedem entrelinhas mais amplas que as serifadas ${ }^{23}$.

No grid, uma maneira simples de definir a profundidade da coluna é convertêla em um múltiplo da entrelinha, de modo que a mancha gráfica acomode um número

\footnotetext{
${ }^{20}$ BRINGHURST, 2005, p.34

${ }^{21}$ BRINGHURST, 2005, p. 43.

22 MULLER-BROCKMANN, 2007, p. 34

${ }^{23}$ BRINGHURST, 2005, p. 43.
} 
inteiro de linhas de texto, como exemplificado na figura 2a. Para chegar a este resultado, na maioria das vezes é necessário fazer um ajuste nas margens inicialmente propostas, pois é extremamente improvável que as mesmas tenham gerado uma altura de coluna que coincida com um múltiplo da entrelinha. Neste caso, deve-se optar pelo número inteiro mais próximo que seja divisível pela entrelinha ${ }^{24}$.

Adicionalmente, caso o projeto necessite de um nível de controle maior do que o fornecido por um grid de colunas, pode-se adicionar diversas subdivisões horizontais que cortam as colunas em linhas, dando origem a um grid modular ${ }^{25}$. Neste caso, a definição da altura dos módulos também poderá ser feita com base na entrelinha, de modo que cada módulo contenha um número inteiro de linhas, havendo entre eles uma linha de espaço em branco ${ }^{26}$, como mostrado na figura $2 b$.

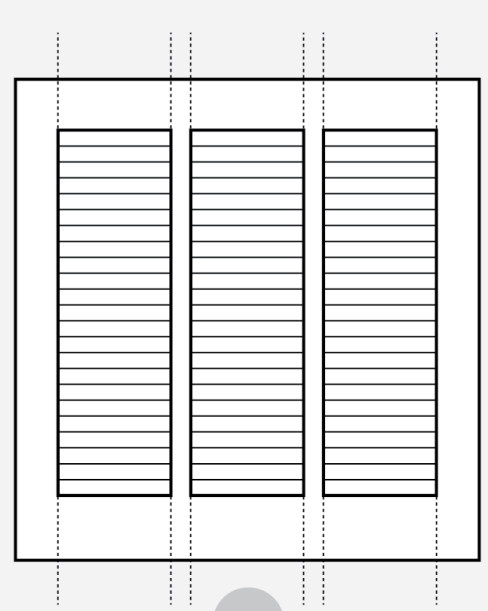

a

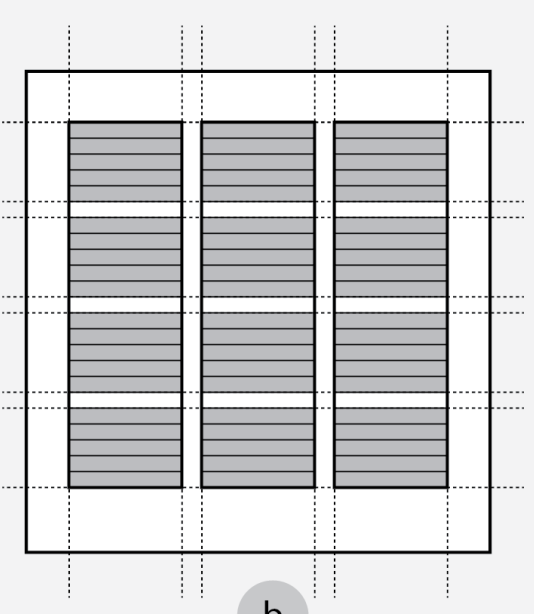

b

Figura 2 - Grid de Colunas e Grid de Módulos ajustados pela entrelinha.

Fonte: Adaptado de HASLAM (2007, p.56)

\section{CONSTRUINDO O GRID DIGITAL}

Conforme explicitado nos exemplos impressos, a construção do grid consiste basicamente na demarcação do formato para a criação de colunas ou módulos, a serem preenchidas com linhas de texto e imagens. O refinamento mútuo entre formato, margens, número de colunas e tipografia é uma das questões centrais na definição do grid.

No impresso, a publicação pode ser projetada de fora para dentro, partindo-se da seleção do formato para depois configurar as margens, colunas e tipografia. Também é possível fazer o inverso, partindo-se da tipografia, passando pelo número de colunas e pela configuração das margens, para posteriormente chegar ao formato final $^{27}$. No entanto, em ambos os casos se tem um controle preciso sobre o material que chegará às mãos do leitor.

Em um projeto digital, é preciso saber abrir mão deste controle estrito e tratar a diversidade, tendo como meta assegurar uma boa leitura em todos os casos. Um

\footnotetext{
${ }^{24}$ HASLAM, 2007, p.57

${ }^{25}$ SAMARA, 2005, p. 28

${ }^{26}$ HASLAM, 2007, p.57

${ }^{27}$ HASLAM, 2007, p. 62
} 
layout de três colunas pode funcionar bem em um tablet como o IPad, empunhado na horizontal, não sendo, por outro lado, adequado para um smartphone. Suas dimensões menores não permitem exibir três colunas com texto legível dentro da métrica de $40 \mathrm{a}$ 50 caracteres por linha. As próprias dimensões do dispositivo pedem outra colunagem.

Desta forma, o layout digital deve ser abordado através do estabelecimento de grupos de dispositivos com tamanhos de tela próximos, dentro dos quais se pode trabalhar um mesmo padrão de colunagem, tipografia e disposição de conteúdo. Esta definição dos grupos a serem contemplados pela publicação deve ser feita com base no público-alvo e estabelecerá as variações de layout a serem tratadas no projeto. A ideia não seria diferenciar por tipo de dispositivo, criando-se categorias como celular, tablet, notebook e desktop, pois os tamanhos de tela se sobrepõem e já existem celulares praticamente do tamanho de tablets, tablets maiores que certos modelos de notebooks, bem como notebooks maiores que certos desktops. O quadro 1 apresenta os grupos de dispositivos comumente usadas para layout em projetos web.

Quadro 1 - Lista com agrupamentos de dispositivos para elaboração de layout.
\begin{tabular}{|c|l|}
\hline 1 & Smartphones empunhadas em modo retrato (vertical) \\
\hline 2 & Smartphones empunhadas em modo paisagem (horizontal) \\
\hline 3 & Tablets pequenos, como o Amazom Kindle, empunhados em modo retrato \\
\hline 4 & Tablets de 10" como o IPad, empunhados em modo retrato \\
\hline 5 & $\begin{array}{l}\text { Tablets como o IPad, empunhadas em modo paisagem, assim como certos notebooks, } \\
\text { netbooks e desktops }\end{array}$ \\
\hline 6 & Telas widescreen, como as presentes em notebooks e desktops. \\
\hline
\end{tabular}

Fonte: MARCOTTE (2011, p.114)

É importante observar que estas faixas não definem layouts necessariamente distintos, e sim indicam que cada grupo requer adaptações para assegurar leiturabilidade. Por exemplo, é possível usar uma única coluna de texto tanto em telas de smartphones em modo paisagem e retrato, quanto em tablets em modo retrato. $\mathrm{A}$ diferença estará na relação entre corpo e comprimento de linha. Em um smartphone retrato pode-se, por exemplo, trabalhar com um corpo de fonte que gere uma linha curta com cerca de 40 caracteres (figura 3a).

Nos smartphones em paisagem, pode-se manter o comprimento da linha em caracteres, aumentando a fonte para ocupar a área maior (figura 3b), ou ainda manter o corpo usado no modo retrato permitindo o aumento do número de caracteres por linha (figura 3c). Em tablets pequenas na vertical, pode-se buscar a linha ideal de 66 caracteres (figura 3d). As tablets maiores como o IPad, empunhadas na vertical, podem tanto ser usadas em layouts com uma coluna, fazendo-se o ajuste das margens e do tamanho da fonte para gerar o comprimento de linha adequado (figura 3e) quanto serem divididas em duas colunas (figura 3f). Por outro lado, tablets na horizontal, assim como telas widescreen, oferecem uma área de visualização que exigiria uma tipografia com corpo muito grande para diagramação em uma única coluna, sendo, normalmente dividida em duas ou três colunas (figuras $3 g$, $3 \mathrm{~h}$ e $3 \mathrm{i}$ ).

Ainda a respeito da colunagem nos dispositivos, é importante observar que as divisões apresentadas não se constituem em uma regra, mas em uma demonstração de como as métricas de comprimento de linha podem ser aplicadas para orientar o layout em dispositivos digitais. 


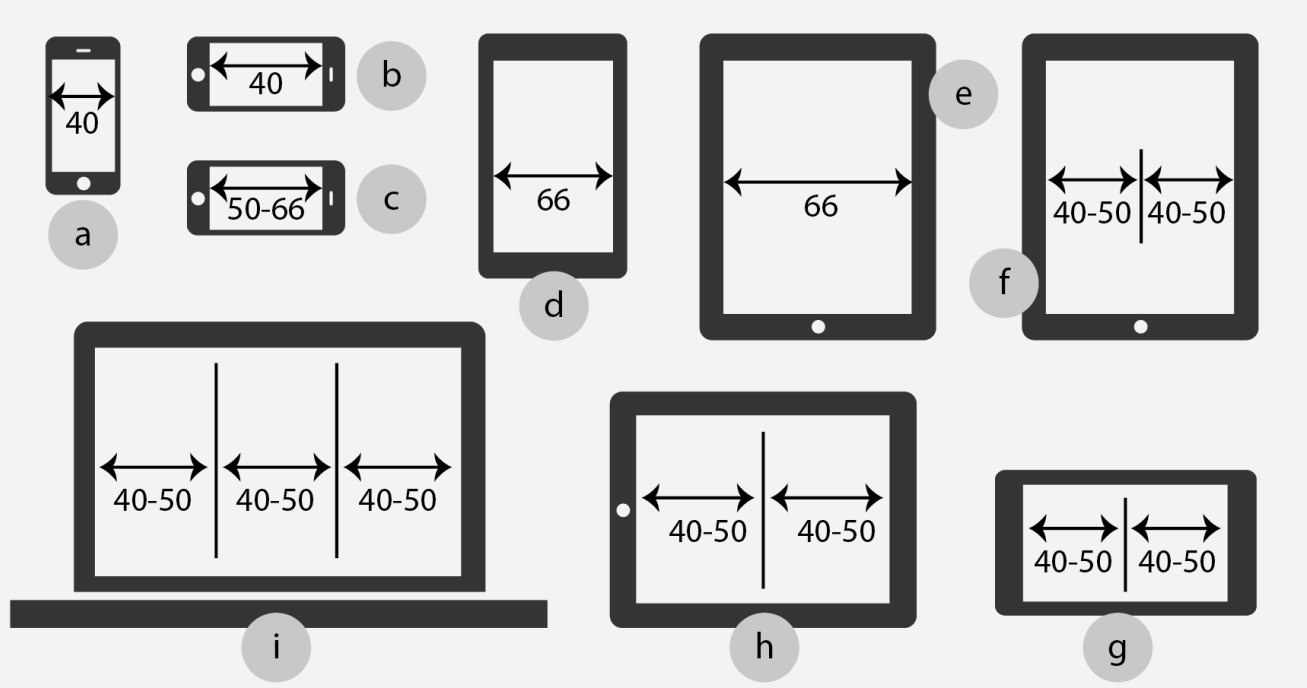

Figura 3 - Exemplos de largura de colunas em números de caracteres em dispositivos digitais. Fonte: Elaborado pelo autor, com base na pesquisa realizada.

A respeito da medida vertical da mancha gráfica, a grande variação no tamanho dos dispositivos impede um controle do número exato de linhas que serão exibidas na tela. Ou, posto de outra forma, no momento do projeto não se sabe quanto da tela será ocupado por um texto selecionado para uma página, podendo a mesma ficar incompleta ou ser extrapolada. Neste sentido, pode-se tratar esta questão de três formas. A primeira consiste em simplesmente abolir o conceito de página e deixar que o conteúdo flua continuamente e seja acessado através de rolagem de tela. Esta abordagem é o padrão na web e é bastante comum em aplicativos voltados para notícias, como os dos jornais "New York Times"(figura 4a) e "BBC News".

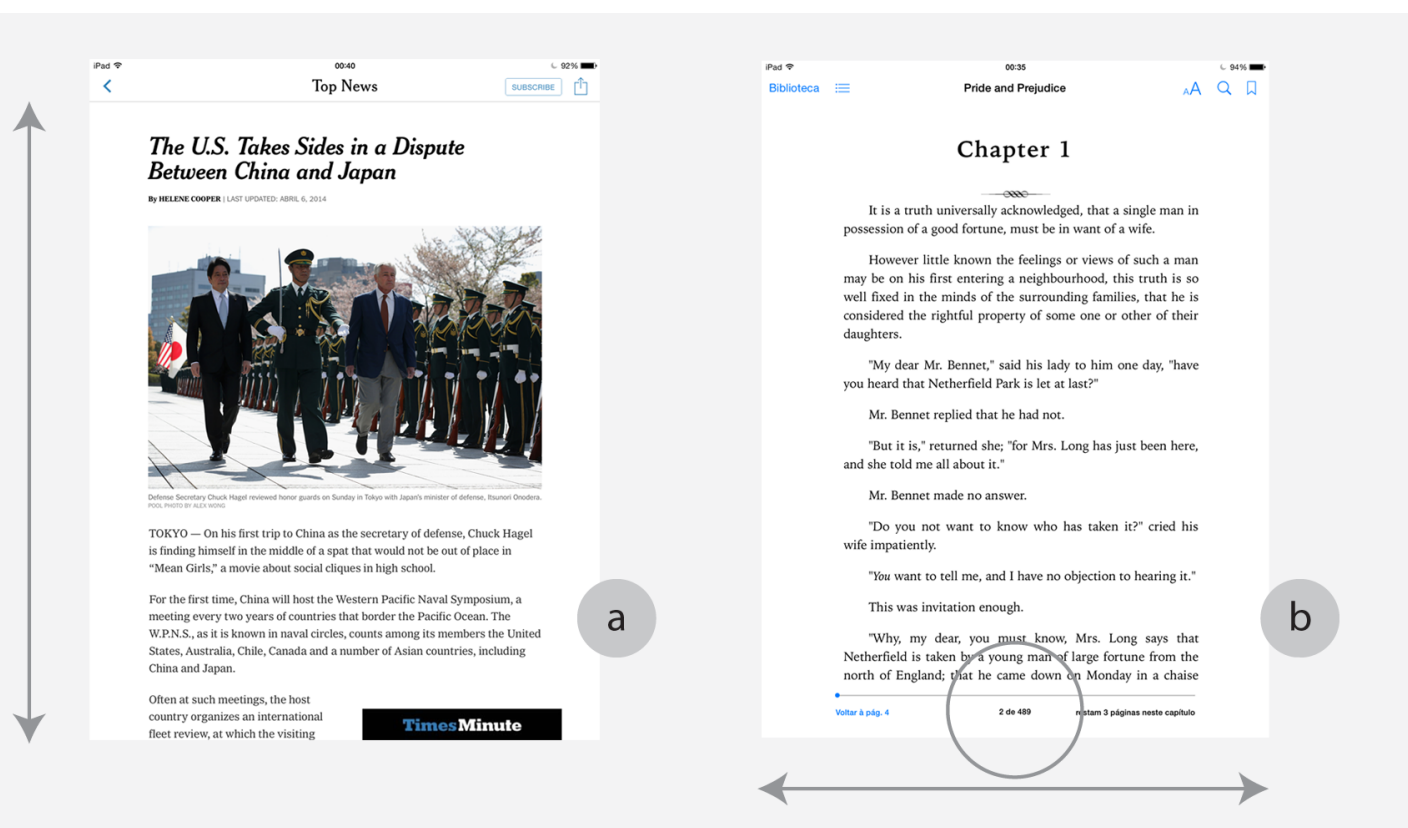

Figura 4 - Capturas de telas dos aplicativos de notícias do New York Times, com rolagem vertical, e do aplicativo de leitura iBooks, com paginação horizontal.

Fonte: 4a)Capturado do aplicativo do jornal New York Times para iPad e 4b) iBook 
A segunda possibilidade consiste no tratamento dinâmico da informação, na qual o aplicativo responsável pela exibição do conteúdo detecta o espaço disponível na tela e gera a paginação requerida. Esta proposta corresponde ao comportamento padrão dos leitores de e-books como o "iBooks"(figura 4b) e o "Kindle", que permitem ainda que o leitor ajuste o corpo do texto e a entrelinha de acordo com suas preferências de leitura, gerando uma nova paginação. É importante observar que esta abordagem pressupõe um fluxo contínuo de conteúdo, no qual as imagens, quando presentes, estão intercaladas com o texto e fluem ao longo das colunas e das páginas. É uma abordagem bem mais simples do que a normalmente é encontrada na diagramação de páginas de uma revista impressa, que costuma conter informações contínuas circundadas por segmentos de informação relacionados, mas que não integram esse fluxo, como imagens e caixas de texto.

A terceira abordagem consiste na definição estática do conteúdo e layout da página no momento da diagramação. Neste caso, faz-se necessário o uso de rolagem nos blocos de texto da página para acomodar a variação da profundidade de coluna de acordo com o tamanho da tela (figura 5a). Assim, tem-se um esquema mais complexo de navegação, no qual a paginação pode acontecer horizontalmente ou verticalmente e, além disso, dentro de cada página pode haver rolagem de conteúdo. Diversas revistas da Editora Abril, como a "Cláudia", adotavam esta abordagem no momento de elaboração deste artigo. Inclusive, no caso da "Cláudia" em particular, a paginação ocorre tanto no sentido vertical, para avançar entre as diversas páginas de uma mesma matéria ou sessão, quanto no sentido horizontal, para trocar de matéria ou sessão, (figura 5b).

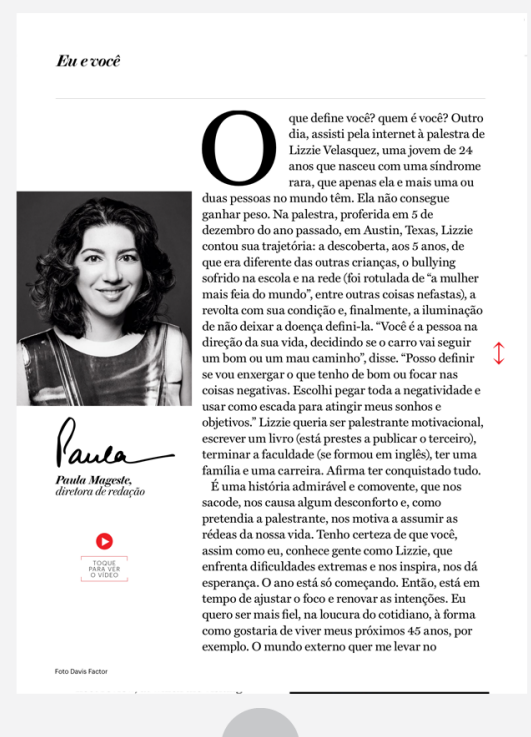

a

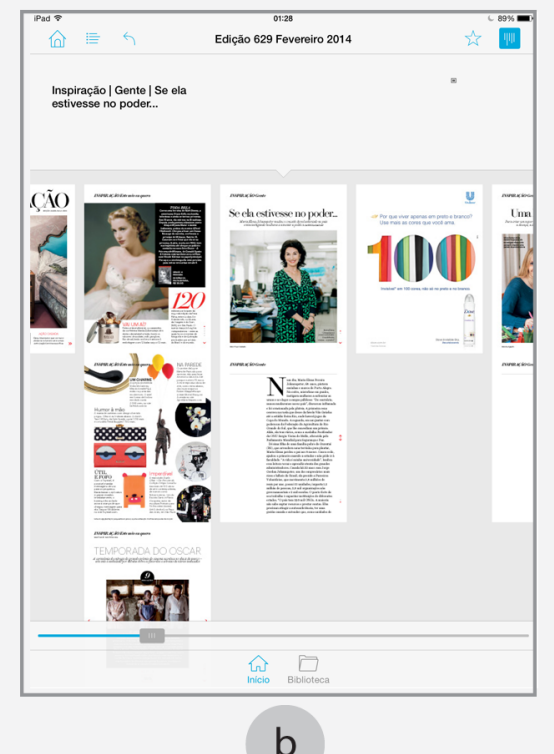

b

Figura 5 - Versão digital da revista Cláudia, destacando-se (a) rolagem vertical apenas no bloco de texto principal da página, indicada por seta vermelha, (b) Visão em zoom out da revista, com navegação horizontal entre matérias, que se encontram verticalmente paginadas.

Fonte: Capturado do aplicativo Iba Revistas para iPad.

Assim, se nas revistas impressas tem-se as cartolas e os números de páginas para guiar a navegação, este modelo de interação requer uma série de indicações 
visuais para o leitor compreender quais blocos de texto contém rolagem, quais matérias ou sessões possuem paginação vertical, bem como lembretes de que é necessário passar horizontalmente para trocar de matéria ou sessão. Desta forma, a qualidade da experiência de leitura digital dependerá tanto de uma diagramação e composição tipográfica assertivas, quanto de um sistema de navegação bem planejado e adequadamente explicitado para o usuário.

\section{CONSIDERAÇÕES FINAIS}

Há quase duas décadas o mercado editorial vem explorando as possibilidades de disponibilizar a informação a seus leitores na plataforma digital. Os últimos anos trouxeram grandes inovações tecnológicas em novos equipamentos, resultando em maior qualidade no suporte da informação e conforto aos usuários no ato da leitura na tela. Observa-se um período de grandes transformações para o mercado editorial, que está migrando fortemente do meio impresso para o meio digital. No entanto, a conquista tecnológica de definição de telas não garante por si só a boa legibilidade e leiturabilidade do texto. Assim como no caso do impresso, a mancha gráfica está nas mãos do designer, que ciente tanto dos princípios tipográficos quanto das características e restrições do ambiente digital, deve moldar o projeto para alcançar seus objetivos de comunicação. Os princípios da composição tipográfica do meio impresso continuam os mesmos para o meio digital e o desafio para os designers está em desenvolver projetos editoriais adaptáveis à diversidade cada vez maior de suportes.

\section{REFERÊNCIAS}

ADG - ASSOCIAÇÃO DOS DESIGNERS GRÁFICOS (Brasil). ABC da ADG: glossário de termos e verbetes utilizados em Design Gráfico. São Paulo: ADG, 2000. 117 p.

ALLIANCE FOR AUDITED MEDIA. The Top 25 U.S. Consumer Magazines for June 2013. Arlington Heights: Alliance for Audited Media, 2013. Disponível na internet por http em:<http://www.auditedmedia.com/news/blog/2013/august/the-top-25-usconsumer-magazines-for-june-2013.aspx >. Acesso em 15mar. 2014

BRINGHURST, Robert. Elementos do estilo tipográfico. 1a ed. São Paulo: Cosac Naify, 2005. 428p.

CHAPPELL, Warren; BRINGHURST, Robert. A short history of the printed word. 2a ed. Canadá: Hartley e Marks Publishers, 1999. 313p.

DECKMANN, S.M. ; POMILIO J. A. O efeito da cintilação luminosa: causas, efeitos e soluções. Disponível na internet por http em: <http://www.dsce.fee.unicamp.br/ حantenor/pdffiles/qualidade/a3.pdf>. Acesso em 20mar. 2014

GOMES FILHO, João. Gestalt do objeto: Sistema de Leitura Visual da Forma. São Paulo: Editora Escrituras, 2000.

HASLAM, Andrew. O livro e o designer II. 1a ed. São Paulo: Edições Rosari, 2007. 256p. 
MARCOTTE, Ethan. Responsive Web Design. New York: A Book Apart, 2011. 150p.

MULLER-BROCKMANN, Josef. Grid Systems. Suíça: Niggli, 2007.176 p.

NIELSENa, Jakob. Be Succinct! (Writing for the Web). Fremont: Nielsen Norman Group, 1997. Disponível nainternet por http em: <http://www.nngroup.com/articles/besuccinct-writing-for-the-web/>. Acesso em 15mar. 2014

NIELSENb, Jakob. The End of Legacy Media (Newspapers, Magazines, Books, TV Networks). Fremont: Nielsen Norman Group, 1998. Disponível na internet por http em:<http://www.nngroup.com/articles/the-end-of-legacy-media-newspapersmagazines-books-tv-networks/>. Acesso em 15mar. 2014

NIELSENc, Jakob. Serif vs. Sans-Serif Fonts for HD Screens. Fremont: Nielsen Norman Group, 2012. Disponível na internet por http em: <http://www.nngroup.com/articles/serif-vs-sans-serif-fonts-hd-screens/>. Acesso em 15mar. 2014

OLIVEIRA, Marina. Produção Gráfica para Designers. Rio de Janeiro: 2AB, 2000. 131 p.

SAMARA, Timothy. Making and Breaking the Grid: A Graphic Design Layout Workshop. 1a ed. Gloucester: Rockport Publishers, 2005. 208 p.

THE GUARDIAN. Digital magazines: how popular are they?. London: Guardian News and Media Limited, 2013. Disponível na internet por http em: <http://www.theguardian.com/news/datablog/2013/aug/19/digital-magazinespopular-circulation-figures $>$. Acesso em 15mar. 2014

WHITE, Jan V. Edição e Design. São Paulo: JSN Editora, 2005. 247 p.

WOOD, Sue. Arts and Books: The book Form. Disponível em: http://www.csu.edu.au/ faculty/arts/humss/art317/briefhist.htm. Acessado em 19 de abril de 2007. 